\title{
Correlates of Depression, Anxiety and Stress among Female Students at Al-Jouf University, Saudi Arabia
}

\author{
Doaa M. Abdel-Salam* and Ekram M. Abdel Khalek** \\ *Department of Family and Community Medicine, College of Medicine, Al-Jouf \\ University, Saudi Arabia, **Department of Public Health and Community Medicine, \\ Faculty of Medicine, Assiut University, Egypt
}

Received :June 2016 Accepted : October 2016

\begin{abstract}
Background: There is evidence that university students are at higher risk of psychological problems that may affect their emotional, psychosocial and physical health. Objectives: This study has been conducted to determine the prevalence of depression, anxiety and stress among female students at Al-Jouf University, Saudi Arabia and to identify their associated factors. Methods: The present study was descriptive cross sectional conducted among female students enrolled at Al-Jouf University. Two self-administered questionnaires have been used, the first is a structured one for identifying sociodemographic characteristics and risk factors of psychological illness among students, and the second is the Arabic version of Depression Anxiety Stress Scale (DASS21). Statistical analysis was done using SPSS version 16. Results: The mean age of the studied students was $21.23 \pm 1.50$. The prevalence of depression, anxiety and stress among students was $75.3 \%, 84.7 \%$ and $41.8 \%$ respectively. Symptoms of moderate severity were predominant among students considered as having depression while, symptoms of extreme severity were predominant among students considered as having anxiety. Most of the students suffered from double and triple psychological illnesses. Sociodemographic, behavioral and medical factors have been significantly associated with the studied psychological illnesses such as number of sleeping hours per day, feeling loneliness, frequent drinking of coffee and presence of chronic physical and psychological illnesses. Conclusion: There is a need for intervention programs and appropriate support services targeting the university students.
\end{abstract}

Key words: Depression, anxiety, stress, university students, Saudi Arabia. Corresponding Author: Doaa M. Abdel-Salam doodyas2004@yahoo.com

\section{Introduction}

University students have to adapt to various psychosocial changes besides coping with the academic and social demands in preparing for their professional careers ${ }^{[1]}$. The high expectation of academic achievement has created a very stressful environment, which if left untreated can be hazardous to their physical and mental health. The common psychological problems among students are depression, anxiety and stress ${ }^{[2]}$. Many studies have revealed that students' performance in school, college and university are affected by symptoms of depression ${ }^{[3]}$, anxiety ${ }^{[4]}$ and stress ${ }^{[5]}$ which may impair their academic achievement [6], lead to deterioration in relationships ${ }^{[7]}$, marital problems and affect future employment ${ }^{[8]}$. Western data suggest that females experience high levels of stress as compared to males. The possible reasons explained by different studies are: females are more likely to report concerns about the volume and 
complexity of the material they had to cover, they are also more likely to report stress due to self-expectation and feeling of lack of competence and tendency for women to over report medical and psychological symptoms [9]. Several studies reported that females have higher level of depression, anxiety and stress which can be attributable to biopsychosocial factors such as social roles and physiological status ${ }^{[10]}$. A study conducted by Bayram and Bilgel ,2008 reported that the prevalence of depression, anxiety and stress, was $27.1 \%, 47.1 \%$ and $27.0 \%$ respectively among a group of Turkish university students ${ }^{[11]}$. Other studies reported high rates of psychological morbidity among university students globally ${ }^{[12-15]}$. A study was done among first year students in an Egyptian public university revealed that the prevalence of depression, anxiety and stress was 63.6, 78.4 and $57.8 \%$ respectively ${ }^{[16]}$. Many studies were conducted in Saudi Arabia assessing psychological problems of university students. A study conducted in Al-Ahsa, Saudi Arabia showed that the prevalence of symptoms of any depression or anxiety was $21.9 \%$. This study revealed that female gender, financial and personal problems were significant predictors for major depression [17]. A study conducted in Taif area, Saudi Arabia revealed that $42.9 \%, 54.9 \%$ and $23.1 \%$ of the students had significant depression, anxiety and obsessive compulsive symptoms respectively ${ }^{[18]}$. Also, a study was done in Abha, Saudi Arabia found that $41.5 \%, 66.2 \%$ and $52.5 \%$ of the students had depression, anxiety and stress respectively ${ }^{[19]}$. Depression, anxiety and stress represent escalating mental health problems among university students especially among females. In addition, extremely limited studies have been conducted among university students in AlJouf region, KSA. So, the present study was designed to determine the prevalence of depression, anxiety and stress among female students at AlJouf University, Saudi Arabia and to identify their associated factors.

\section{Population and Methods:}

1- Setting: The Kingdom of Saudi Arabia (KSA) has a population of 31 million people and is one of the countries experiencing demographic transition in its population structure. AlJouf University in AlJouf region is located in the Northern province of KSA. The female campus contains 8 colleges: Medicine, Science, Applied Medical Sciences, Pharmacy, Administrative Sciences, Education, Computer Science and Sharia. The total number of female students enrolled in AlJouf University according to registries for the academic year 20142015 was 7042.

2- Study design and sampling: A crosssectional descriptive study design was used. The sampling frame consisted of all female students at different colleges and grades were the target population. The sample size was calculated using $N=\frac{P(1-P) Z^{2}}{d^{2}} \quad$ assuming the prevalence of depressive and anxiety symptoms to be $40 \%{ }^{[18]}$ with a precision of 5\%, applying a confidence level of $95 \%$ and $80 \%$ power of the study. The calculated sample size was 368 however, 340 questionnaires were completed yielding a response rate $92 \%$.

A multistage proportionate sampling method was therefore applied. A sampling fraction was calculated to select participants in relation to the population in each college. For each college, students were chosen using a systematic random sampling technique (using the academic identification number) from the available registries. 
The timing of the study was chosen to avoid the beginning and end of the semester, when students are typically undergoing a variety of stresses associated with moving, settling into a routine, or preparing for final exams.

3-Instrument: The data collection instrument was composed of two selfadministered questionnaires. The first is a structured self-generated for identifying sociodemographic characteristics and risk factors of psychological illness among the students. The second is the Arabic short version of the standardized Depression Anxiety Stress Scale (DASS) which is a 21 item questionnaire. DASS-21 is a set of three self-report scales designed to identify the presence and measure severity of the negative emotional states of depression, anxiety and stress, seven items per scale ${ }^{[20]}$. The DASS-21 has been well accepted globally and is a reliable easy screening instrument. The items in the depression scale focused on low mood, low self-esteem and poor outlook for the future. The anxiety scale items focused on fear response and psychological arousal, while the stress scale was on persistent arousal and tension ${ }^{[21]}$. The students were asked to rate the extent to which they have experienced various symptoms over the past one week. Each item was scored on a 4-point Likert scale $(0=$ Did not apply to me at all, $1=$ Applied to me to some degree, or some of the time, $2=$ Applied to me to a considerable degree, or a good part of time, and $3=$ Applied to me very much, or most of the time). Based on the manual guidelines, scores from each subscale were summed up and multiplied by two to suit the original 42-items. Each subscale score will range between 0 and 42 and higher scores indicated greater levels of distress ${ }^{[20]}$. For the depression scale, scores of 9 or less were considered 'normal', 10-13 were 'mild', 14-20 were 'moderate', 21-27 were 'severe' and scores greater than 28 were considered 'extremely severe'. For anxiety scale, scores less than 7 were considered 'normal', 8-9 were 'mild', 10-14 were 'moderate', 15-19 were 'severe' and those above 20 were considered 'extremely severe'. For the stress scale, scores less than 14 were considered 'normal', 15-18 were 'mild', 19-25 were 'moderate', 26-33 were 'severe' and scores greater than 34 were considered 'extremely severe' ${ }^{[20]}$.

\section{Ethical Consideration}

Prior ethical approval was obtained from the Ethics Committee of the College of Medicine at AlJouf University. The female students have been invited to participate in the study after explaining the purpose of the study and emphasizing the confidentiality of the collected data through anonymous self-administered questionnaires. The participation of the students in the present study was optional and based on informed verbal consent. Administrators of the University were informed about the study and its purposes.

Statistics: Statistical analysis was performed using the Statistical Package of Social Science (SPSS) version 16. Descriptive statistics were performed. Comparison between groups was done using chi-square and Fisher's Exact tests for qualitative variables. Logistic regression analysis was done to detect risk factors of depression, anxiety and stress. P-value was considered statistically significant when it is less than 0.05 .

\section{Results}

The sociodemographic and psychological characteristics of the respondents are presented in Table (1). A total number of 340 students have been participated in the present study. Their mean age was $21.23 \pm 1.50$ with a range of 19-25 years. Majority of the students $(82.6 \%)$ were not married. 
Regarding the living arrangements, most of the students were living with their families (93.8\%) except small percentage of them were living with friends $(3.8 \%)$ or in university housing $(2.4 \%)$. The number of sleeping hours per day was 7-8 hours among $41.5 \%$ of them. The family income was considered sufficient by most of the students (92.4\%). Depression, anxiety and stress have been reported among $75.3 \%, 84.7 \%$ and $41.8 \%$ of the students respectively. Single, double and triple psychological illnesses have been reported among $19.1 \%, 34.4 \%$ and $37.9 \%$ of the students respectively.

Table (2) demonstrated the impact of sociodemographic characteristics of the students on depression, anxiety and stress. Statistical significant differences were found between symptoms of depression, anxiety and stress on one hand and the number of sleeping hours per day on the other hand. The symptoms of depression, anxiety and stress were less frequent among student who slept 7-8 hours. On the depression scale, $66 \%$ of the students who slept 7-8 hours had depression against $79.2 \%$ and $84.5 \%$ for students with longer and shorter sleeping durations respectively $(\mathrm{p}=0.002)$ Regarding anxiety, $78.7 \%$ of those who slept 7-8 hours had anxiety versus $87.5 \%$ of those who slept 9 or more hours and $90.3 \%$ of those who slept less than 6 hours $(\mathrm{p}=0.03)$. In stress, $33.3 \%$ of those who slept 7-8 hours had stress versus $52.1 \%$ of those who slept 9 or more hours and $43.7 \%$ of those who slept less than 6 hours $(\mathrm{p}=0.01)$. Regarding feeling loneliness of the students, $85.5 \%$ and $60.9 \%$ of the students who felt lonely had depression and stress respectively versus $72.7 \%$ and $36.9 \%$ who didn't feel lonely with statistical significant differences $\quad(p=0.028, \quad p=0.000$ respectively). The behavioral and medical factors and their relationship with depression, anxiety and stress have been reported in Table (3). Depression was significantly associated with the frequent drinking of coffee and tea as $79.2 \%$ of the students who drank coffee and tea had depression versus $65.3 \%$ who didn't $(\mathrm{p}=0.008)$. Depression and stress were significantly associated with the presence of chronic physical illness. All students suffered from the presence of chronic physical illness had depression versus $74.2 \%$ who didn't $(\mathrm{p}=0.05)$. Also, $80 \%$ of the students suffered from chronic physical illness had stress versus $40 \%$ who didn't $(\mathrm{p}=0.002)$. Table (3) also showed that stress was significantly associated with the presence of chronic psychological illness as $88.5 \%$ of the students suffered from chronic psychological illness had stress versus $37.9 \%$ who didn't $(p=0.000)$. Table (4) shows that sleeping hours $\leq 6$ hours was a significant predictor for depression and anxiety. However, the table reveals that the presence of chronic psychological illness and feeling loneliness were significant predictors for stress.

Figure (1) showed that symptoms of moderate severity were predominant among students considered as having depression (30.3\%) whereas, symptoms of extreme severity predominant among students considered as having anxiety $(39.4 \%)$.

Figure (2) reveals that there were highly significant positive correlations between depression score and both anxiety and stress scores $(\mathrm{P}=0.000)$. Also, there was highly significant positive correlation between anxiety score and stress score $(\mathrm{P}=0.000)$.

\section{Discussion}

The present study aimed to assess depression, anxiety and stress among female students at AlJouf University, Saudi Arabia. In this study, the prevalence of depression, anxiety and stress was $75.3 \%, 84.7 \%$ and $41.8 \%$ respectively. This is higher than other 
studies using similar instruments. Shamsuddin et al., 2013 reported that the prevalence of depression, anxiety and stress among Malaysian university students was $37.2 \%, 63 \%$ and $23.7 \%$ respectively ${ }^{[22]}$. Bayram and Bilgel, 2008 found that $27.1 \%, 47.1 \%$ and $27 \%$ of the students had depression, anxiety and stress respectively in Turkey ${ }^{[11]}$. The prevalence of depression, anxiety and stress in this study is also higher than other studies from similar sociocultural backgrounds. A study conducted among Saudi University students revealed that the prevalence of depression and anxiety was $24.4 \%$ and $18 \%$ respectively ${ }^{[17]}$. Also, an Egyptian study found the prevalence of depression, anxiety and stress among Egyptian medical students as 63.6, 78.4 and $57.8 \%$ respectively ${ }^{[16]}$. The high prevalence of symptoms of depression and anxiety among the studied girls could be due to the stresses faced by Saudi females as a result of the cultural and social changes in the Saudi society [23]. Another study explained this in light of the complexity of the Saudi job market for women, which makes choosing a career more difficult ${ }^{[24]}$. Other causes may be fear of making mistakes, feelings of inadequacy, or fear of unemployment after graduation, which are factors leading to distress in students in this age group ${ }^{[25]}$. Although the DASS questionnaire is not a diagnostic instrument, the rates of depression, anxiety and stress symptoms highlight the need for attention from health care professionals and the university administrative personnel.

Regarding the severity of symptoms of the psychological illnesses, this study revealed that $30.3 \%$ of the students had moderate depression while, $39.4 \%$ had extremely severe anxiety. These results are different from other studies. In a study conducted in Abha in Saudi Arabia, $14 \%$ of students showed moderate symptoms of depression while $11 \%$ of them showed extremely severe symptoms of anxiety ${ }^{[19]}$. Also, $63.8 \%$ and $36.2 \%$ of the students complained of mild and severe depression respectively in a study done among Saudi secondary school girls in Taif area [18]. However, a study conducted among first year medical students in an Egyptian public university showed that symptoms of moderate severity were the predominant among students having depression, anxiety and stress ${ }^{[16]}$. The marked diversity in these studies results could be attributed to the difference in methodology used, case definition, method of collecting information, sampling procedures, age or the different geographical locations [26, 27]. The present study showed a high occurrence of double and triple psychological illnesses among the studied students which is a finding observed in studies carried out on Saudi adolescents [18, 19]. This could be attributed to many factors such as the overlapping diagnostic criteria, genetics, neurophysiology, neurochemistry, negative affect, temperament, perceived control, or to the interpersonal mechanisms ${ }^{[28,29]}$. In the same time, previous studies have shown that the presence of anxiety symptoms increases the chance of developing depressive symptoms ${ }^{[30]}$. The current study investigates the effect of sleeping hours per day on depression, anxiety and stress and demonstrates its statistical significance. As students who slept 7-8 hours, which is the ideal sleeping hours per day were less liable to depression, anxiety and stress. These findings suggest that adolescents who don't sleep ideal sleeping hours may represent a group at increased risk of experiencing mental health problems. Many studies showed that insomniacs are more likely to report anxiety and depression and to 
perceive their lives as being more stressful compared to good sleepers [31, 32]. A study done by Richards and Smith, showed that few sleeping hours are among the risk factors of depression, anxiety and stress in adolescent population ${ }^{[33]}$.

Depressed and distressed students in the present study complained feeling loneliness in significant excess than normal students in agreement with a study conducted by Abdallah and Gaber [16]. Students who consumed frequent coffee or tea had higher depressive symptoms in the present study in consistent with a study conducted by Loke [34]. However other studies revealed an inverse relationship between tea, coffee consumption with depression and anxiety ${ }^{[35-37]}$.

Depression and anxiety are common in persons with physical illnesses and have a significant association with physical health ${ }^{[38]}$. Key findings from eighteen surveys across 17 countries in Europe, the Americas, the Middle East, Africa, Asia, and the South Pacific indicated that the risk of depression, anxiety and stress are higher among persons with diabetes, as compared to the persons without diabetes ${ }^{[39]}$. This is comparable to the results of the present study which showed that depression and stress were significantly higher in the presence of chronic physical illnesses. Psychological illnesses can lead to negative outcomes including impairment in ability to work efficiently, deterioration in relationships, medical school dropout and other health problems ${ }^{[40]}$. In this study, Psychological illnesses are more prevalent in distressed students and this is consistent with a study conducted by Abdallah and Gaber ${ }^{[16]}$.

Limitations of the study: The educational authorities in KSA prevent female researchers from conducting studies on male students. That is why the researches did not have the opportunity to determine sex specific prevalence rates. In addition, the use of DAAS which is a self-reporting data collection tool necessitates psychiatric evaluation through structured clinical interview for final diagnosis.

Conclusion: Psychological illnesses in the form of depression, anxiety, and stress have been reported in a significant proportion of female students at AlJouf University, Saudi Arabia. Depression symptoms has been reported in $75.3 \%$ of students while, anxiety and stress symptoms were found in $84.7 \%$ and $41.8 \%$ of the students respectively. Nearly $40 \%$ of students suffered from extremely severe symptoms of anxiety whereas, 30.3\% suffered from moderate depression. Concomitant presences of double and triple psychological illnesses were present among $34.4 \%$ and $37.9 \%$ of the students respectively. Sociodemographic, behavioral, and medical factors have been found to be significantly associated with the studied morbidities such as number of sleeping hours per day, feeling loneliness, frequent drinking of coffee or tea and the presence of chronic physical and psychological illnesses. There is a need for an organized intervention program for promotion of the mental health of university students.

\section{Acknowledgement}

The authors acknowledge Dr. Naif Alwakid, Dean of College of Medicine, AlJouf University, AlJouf, Saudi Arabia, for facilitating conduction of the present study. Deep thanks to the university authorities and students for their cooperation.

\section{References}

1. Uehara $\mathrm{T}$, Takeuchi $\mathrm{K}$, Kubota $\mathrm{F}$, Oshima K, Ishikawa O. Annual transition of major depressive episode in university students using a structured self-rating 
questionnaire. Asia Pacific Psychiatry 2010; 2: 99-104.

2. Dyrbye LN, Thomas MR, Shanafelt TD. Systematic review of depression, anxiety, and other indicators of psychological distress among U.S. and Canadian medical students. Academic Medicine 2006; 81: 354-373.

3. Stark KD, Brookman CS. Theory and family-school intervention. In: Fine JM, Carlson C (Eds.). The Handbook of Family-school Intervention. 1994.

4. Anson O, Bernstein J, Hobfoll SE. Anxiety and performance in two ego threatening situation. Journal of Personality Assessment 1984; 48: 168-172.

5. Dusselier L, Dunn B, Wang Y, Shelley II MC, Whalen DF. Personal health, academic, and environmental predictors of stress for residence hall students. Journal of American College Health 2005; 54: 15-24.

6. 6) Stewart-Brown S, Evans J, Patterson J, Petersen S, Doll H, Balding J, Regis D. The health of students in institutes of higher education: an important public health problem. Journal of Public Health Medicine 2000; 22: 492-499.

7. Ali BS, Rahbar MH, Naeem S, Tareen AL, Gui A, Samad L. Prevalence of and factors associated with anxiety and depression among women in a lower middle class semi-urban community of Karachi, Pakistan. Journal of the Pakistan Medical Association 2002; 52: 513-517.

8. Eisenberg D, Golberstein E, Gollust S, Hefner J. Prevalence and correlates of depression, anxiety and suicidality among university students. American Journal of Orthopsychiatry 2007; 77: 534-542.

9. Verbuegge LM, Gender and health: an update on hypothesis and evidence. Journal of Health and Social Behavior 1985; 26:156-182.

10. Bangasser DA, Curtis A, Reyes BA, Bethea T, Parastatidis I, Ischiropoulos H, Van Bockstaele EJ, Valentino RJ. Sex differences in corticotrophin releasing factor receptor signaling and trafficking: potential role in female vulnerability to stress related psychopathology. Molecular Psychiatry 2010; 15: 896-904.

11. Bayram N, Bilgel N. The prevalence and sociodemographic correlations of depression, anxiety and stress among a group of university students. Social Psychiatry and Psychiatric Epidemiology 2008; 43:667-672.

12. Adewuya OA, Ola BA, Afolabi O. Validity of the patient health questionnaire (PHQ-9) as a screening tool for depression amongst Nigerian university students. Journal of Affective Disorders 2006; 96 : 89-93.

13. Ovuga E, Boardman J, Wasserman D. Undergraduate student mental health at Makerere University, Uganda. World Psychiatry 2006; 5: 51-52.

14. Tomoda A, Mori K, Kimura M, Takashasi T, Kitamura T. First year prevalence and incidence of depression among first-year university students in Japan: a preliminary study. Psychiatry and Clinical Neurosciences 2000; 54: 583-588.

15. Wong TW, Gao Y, Tam W. Anxiety among university students during the SARS epidemic in Hong Kong. Stress Health 2006; 23: 31-35.

16. Abdallah A, Gabr H, Depression, anxiety and stress among first year medical students in an Egyptian public university. International Research Journal of Medicine and Medical Sciences 2014; 2(1): 11-19.

17. Amr M, Tawfik T, Saddichha S, Al Malki S, Al Samail M, Al Qahtani N, AlAbdulHadi A, Al Shoaibi A. Depression and anxiety among Saudi University students: prevalence and correlates. The Arab Journal of Psychiatry 2013; 24(1): 17.

18. Desouky D, Ibrahem R, Omar M. Prevalence and comorbidity of depression, anxiety and obsessive compulsive disorders among Saudi secondary school girls, Taif Area, KSA. Archives of Iranian Medicine 2015; 18(4):234-238.

19. Al-Gelban K, Al-Amri H, Mostafa O. Prevalence of Depression, anxiety and stress as measured by the Depression, Anxiety, and Stress Scale (DASS-42) among secondary school girls in Abha, Saudi Arabia. SQU Med J 2009; 9(2): 140-147.

20. Loviband SH, Loviband PF. Manual for the Depression Anxiety Stress Scales, second ed. Psychology Foundation, Sydney 1995. 
21. Shea TL, Tennant A, Pallant JF. Rasch model analysis of the Depression, Anxiety and Stress Scales (DASS). BMC Psychiatry 2009; 9 (21).

22. Shamsuddin K, Fadzil F, Salwina W, Shah S, Omar K, Muhammad N, Jaffar A, Ismail A, Mahadevan R. Correlates of depression, anxiety and stress among Malaysian university students. Asian Journal of Psychiatry 2013; 6: 318-323.

23. Meijer R, Reform in Saudi Arabia: the gender segregation debate. Mide East Poli. 2010; 17(4): 80 - 100.

24. Offenhauer $\mathrm{P}$, Women in Islamic societies: a selected review of social scientific literature, A report prepared by the Federal Research Division, Library of Congress under an Interagency Agreement with the Office of the Director of National Intelligence Council (ODNI/ADDNIA/NIC) and Central Intelligence Agency/Directorate of Science \& Technology 2005.Available from URL: http://www.loc.gov/rr/frd/ pdffiles/Woman_Islamic_Societies.pdf.

25. UNICEF. The State of the World's Children. Adolescence: An Age of Opportunity. 2011. Available from URL: http://www.unicef.org/adolescence/files/SO WC_2011_

Main_Report_EN_02092011.pdf.

26. Jacobson L, Churchill R, Donovan C, Garrarda E, Fay J. Tackling teenage turmoil: primary care recognition and management of mental ill health during adolescence. Fam Pract. 2002; 19: 4014 4019.

27. Merikangas K, Knight E. The epidemiology of depression in adolescents. In: Nolen-Hoeksema S, Hilt L, eds, Handbook of Depression in Adolescence, New York, London: Routledge 2009; 53 73.

28. American Psychiatric Association DSM-5 development. Comorbidity of depression and generalized anxiety disorder 2013. Available from URL: http://www.dsm5. org/ research/ pages/ comorbidity of depression and generalized anxiety disorder\% 28june20-22, 2007\% 29. aspx.

29. Alansari BM. Relationship between depression and anxiety among undergraduate students in eighteen Arab countries: a cross cultural study. Soc Beh Personal 2005; 33(5): 503-512.

30. Gallab MA. The relationship between anxiety sensitivity and anxiety, panic and depression among a non-clinical sample in Egypt. Egypt JPsychol Stud. 2002; 12 (37): 48-95.

31. Taylor DJ, Lichstein KL, Durrence $\mathrm{HH}$, Reidel BW, Bush AJ. Epidemiology of insomnia, depression, and anxiety. Sleep 2005; 28(11):1457-1464.

32. Morin CM, Rodrigue S, Ivers H. Role of stress, arousal, and coping skills in primary Insomnia. Psychosom Med. 2003; 65(2): 259-267.

33. Richards G, Smith A. Risk factors for and effects of stress, anxiety, and depression in adolescents. British Journal of Education, Society \&Behavioural Science 2015; 10(4): 1-10.

34. Loke WH. Effects of caffeine on mood and memory. Physiology and Behavior 1988; 144: 367-372.

35. Hozawa A, Kuriyama S, Nakaya N, Ohmori-Matsuda K, Kakizaki M. Green tea consumption is associated with lower psychological distress in a general population: The Ohsaki Cohort Study. American Journal of Clinical Nutrition 2006; 90: 1390-1396.

36. Mirza B, Ikram H, Bilgrami S, Haleem DJ, Haleem MA. Neurochemical and behavioral effects of green tea. Pak J Pharm Sci 2013; 26:511-516.

37. Khademalhossini Z, Ahmadi J, Khademalhosseini Z. Prevalence of tea, coffee and nescafe consumption among high school students and its relationship with depression and anxiety. Sociology and Criminology 2015; 3 (2): 1-6.

38. Stojanović-Tasić M, Grgurević A, Cvetković J, Grgurević U, Trajković G. Association between somatic diseases and symptoms of depression and anxiety among Belgrade University students. Medicinski Glasnik 2014; 11 (2): 373-378.

39. Lin EH, Korff MV, Alonso J, Angermeyer MC, Anthony J, Bromet E, Bruffaerts R, Gasquet I, Girolamo G, Gureje O, Haro JM, Karam E, Lara C, Lee $\mathrm{S}$, Levinson D, Ormel JH, Posada-Villa J, Scott K, Watanabe $M$ and Williams $D$. Mental disorders among persons with diabetes: Results from the World Mental 
Health Surveys. J Psychosom Res 2008; 65:571-580.

40. Murray CJ, Lopez AD. The Global Burden of Disease: A Comprehensive assessment of mortality and disability from diseases, injuries and risk factors in 1990 and projected to 2020, Geneva, Switzerland, World Health Organization 1996. 
Table (1): Socio-demographic and psychological characteristics of the respondents

\begin{tabular}{|c|c|c|}
\hline & No. $(n=340)$ & $\%$ \\
\hline \multicolumn{3}{|l|}{ Age: (years) } \\
\hline $19-20$ & 118 & 34.7 \\
\hline $21-22$ & 148 & 43.5 \\
\hline$>22$ & 74 & 21.8 \\
\hline Mean \pm SD (Range) & \multicolumn{2}{|c|}{$21.23 \pm 1.50(19.0-25.0)$} \\
\hline \multicolumn{3}{|l|}{ Marital status: } \\
\hline Single & 281 & 82.6 \\
\hline Married & 59 & 17.4 \\
\hline \multicolumn{3}{|l|}{ Living arrangement: } \\
\hline Living with family & 319 & 93.8 \\
\hline Living with friends & 13 & 3.8 \\
\hline Living in university housing & 8 & 2.4 \\
\hline \multicolumn{3}{|l|}{ No. of sleeping hours per day: } \\
\hline$\leq 6$ hours & 103 & 30.3 \\
\hline $7-8$ hours & 141 & 41.5 \\
\hline 9 or more & 96 & 28.2 \\
\hline \multicolumn{3}{|l|}{ Family income: } \\
\hline Sufficient & 314 & 92.4 \\
\hline Insufficient & 26 & 7.6 \\
\hline Considered as having depression by DASS 21 & 256 & 75.3 \\
\hline Considered as having anxiety by DASS 21 & 288 & 84.7 \\
\hline Considered as having stress by DASS 21 & 142 & 41.8 \\
\hline \multicolumn{3}{|l|}{ Presence of psychological problems: } \\
\hline Normal & 29 & 8.5 \\
\hline Single illness & 65 & 19.1 \\
\hline Double illness & 117 & 34.4 \\
\hline Triple illness & 129 & 37.9 \\
\hline
\end{tabular}


Table (2): Socio-demographic factors and their relationship with depression, anxiety and stress scores

\begin{tabular}{|c|c|c|c|c|c|c|c|c|c|c|c|c|c|c|c|}
\hline & \multicolumn{4}{|c|}{ Depression } & \multirow{3}{*}{$\begin{array}{l}P \text { - } \\
\text { value }\end{array}$} & \multicolumn{4}{|c|}{ Anxiety } & \multirow{3}{*}{$\begin{array}{l}P \text { - } \\
\text { value }\end{array}$} & \multicolumn{4}{|c|}{ Stress } & \multirow{3}{*}{ P-value } \\
\hline & \multicolumn{2}{|c|}{$\begin{array}{l}\text { Present } \\
(n=256)\end{array}$} & \multicolumn{2}{|c|}{$\begin{array}{l}\text { Absent } \\
(n=84)\end{array}$} & & \multicolumn{2}{|c|}{$\begin{array}{l}\text { Present } \\
(n=288)\end{array}$} & \multicolumn{2}{|c|}{$\begin{array}{l}\text { Absent } \\
(\mathbf{n}=52)\end{array}$} & & \multicolumn{4}{|c|}{$\begin{array}{ll}\text { Present } & \text { Absent } \\
(n=142) & (n=198)\end{array}$} & \\
\hline & $\mathbf{N}$ & $\%$ & $\mathbf{N}$ & $\%$ & & $\mathbf{N}$ & $\%$ & $\mathbf{N}$ & $\%$ & & $\mathbf{N}$ & $\%$ & $\mathbf{N}$ & $\%$ & \\
\hline \multicolumn{16}{|l|}{$\begin{array}{l}\begin{array}{l}\text { Age: } \\
\text { (years) }\end{array} \\
\end{array}$} \\
\hline $19-20$ & 87 & 73.7 & & 26.3 & & 104 & 88.1 & & 11.9 & & 50 & 42.4 & 68 & 57.6 & \\
\hline $21-22$ & 109 & 73.6 & 39 & 26.4 & & 121 & 81.8 & 27 & 18.2 & & 55 & 37.2 & 93 & 62.8 & \\
\hline$>22$ & 60 & 81.1 & 14 & 18.9 & 0.427 & 63 & 85.1 & 11 & 14.9 & 0.354 & 37 & 50.0 & 37 & 50.0 & 0.185 \\
\hline \multicolumn{16}{|l|}{$\begin{array}{l}\text { Living } \\
\text { with: }\end{array}$} \\
\hline Family & 239 & 74.9 & & 25.1 & & 269 & 84.3 & & 15.7 & & 131 & 41.1 & 188 & 58.9 & \\
\hline Others & 17 & 81.0 & & 19.0 & 0.535 & 19 & 90.5 & 2 & 9.5 & $0.753^{\neq}$ & 11 & 52.4 & 10 & 47.6 & 0.308 \\
\hline \multicolumn{16}{|l|}{$\begin{array}{l}\text { Sleeping } \\
\text { hours/day: }\end{array}$} \\
\hline$\leq 6$ hours & 87 & 84.5 & 16 & 15.5 & & 93 & 90.3 & 10 & 9.7 & & 45 & 43.7 & 58 & 56.3 & \\
\hline 7 - 8 hours & 93 & 66.0 & 48 & 34.0 & & 111 & 78.7 & 30 & 21.3 & & 47 & 33.3 & 94 & 66.7 & \\
\hline 9 or more & 76 & 79.2 & 20 & 20.8 & $0.002 *$ & 84 & 87.5 & 12 & 12.5 & 0.031* & 50 & 52.1 & 46 & 47.9 & 0.014* \\
\hline \multicolumn{16}{|l|}{$\begin{array}{l}\text { Family } \\
\text { income: }\end{array}$} \\
\hline Sufficient & 236 & 75.2 & & 24.8 & & 266 & 84.7 & 48 & 15.3 & & 128 & 40.8 & 186 & 59.2 & \\
\hline Insufficient & 20 & 76.9 & & 23.1 & 0.841 & 22 & 84.6 & & 15.4 & 0.989 & 14 & 53.8 & 12 & 46.2 & 0.194 \\
\hline \multicolumn{16}{|l|}{$\begin{array}{l}\text { Friendship } \\
\text { problems: }\end{array}$} \\
\hline Present & 55 & 72.4 & 21 & 27.6 & & 62 & 81.6 & 14 & 18.4 & & 34 & 44.7 & 42 & 55.3 & \\
\hline Absent & 201 & 76.1 & 63 & 23.9 & 0.502 & 226 & 85.6 & 38 & 14.4 & 0.390 & 108 & 40.9 & 156 & 59.1 & 0.551 \\
\hline \multicolumn{16}{|l|}{$\begin{array}{l}\text { Feeling } \\
\text { loneliness }\end{array}$} \\
\hline Yes & 59 & 85.5 & 10 & 14.5 & & 60 & 87.0 & & 13.0 & & 42 & 60.9 & 27 & 39.1 & \\
\hline No & 197 & 72.7 & 74 & 27.3 & $0.028 *$ & 228 & 84.1 & 43 & 15.9 & 0.561 & 100 & 36.9 & 171 & 63.1 & $<0.001 *$ \\
\hline
\end{tabular}


Table (3): Behavioral and medical factors and their relationship with depression, anxiety and stress scores

\begin{tabular}{|c|c|c|c|c|c|c|c|c|c|c|c|c|c|c|c|}
\hline & \multicolumn{4}{|c|}{ Depression } & \multirow{3}{*}{ P-value } & \multirow{2}{*}{\multicolumn{2}{|c|}{\begin{tabular}{|l} 
Anxiety \\
Present \\
$(\mathbf{n}=$ \\
$\mathbf{2 8 8})$ \\
\end{tabular}}} & \multirow{2}{*}{\multicolumn{2}{|c|}{$\begin{array}{l}\text { Absent } \\
(n=52)\end{array}$}} & \multirow{3}{*}{$\begin{array}{l}\text { P- } \\
\text { value }\end{array}$} & \multicolumn{4}{|c|}{ Stress } & \multirow{3}{*}{$\begin{array}{l}\text { P- } \\
\text { value }\end{array}$} \\
\hline & \multicolumn{2}{|c|}{$\begin{array}{l}\text { Present } \\
(n=256)\end{array}$} & \multicolumn{2}{|c|}{$\begin{array}{l}\text { Absent } \\
(n=84)\end{array}$} & & & & & & & \multicolumn{2}{|c|}{$\begin{array}{l}\text { Present } \\
(\mathrm{n}= \\
\mathbf{1 4 2})\end{array}$} & \multicolumn{2}{|c|}{$\begin{array}{l}\text { Absent } \\
(\mathrm{n}= \\
\mathbf{1 9 8})\end{array}$} & \\
\hline & $\mathbf{N}$ & $\%$ & $\mathbf{N}$ & $\%$ & & $\mathbf{N}$ & $\%$ & $\mathbf{N}$ & $\%$ & & $\mathbf{N}$ & $\%$ & $\mathbf{N}$ & $\%$ & \\
\hline $\begin{array}{l}\text { Frequent of } \\
\text { drinking } \\
\text { coffee/ tea: } \\
\text { Yes } \\
\text { No }\end{array}$ & $\begin{array}{l}194 \\
62\end{array}$ & $\begin{array}{l}79.2 \\
65.3\end{array}$ & $\begin{array}{l}51 \\
33\end{array}$ & $\begin{array}{l}20.8 \\
34.7\end{array}$ & $0.008^{*}$ & $\begin{array}{l}208 \\
80\end{array}$ & $\begin{array}{l}84.9 \\
84.2\end{array}$ & $\begin{array}{l}37 \\
15\end{array}$ & $\begin{array}{l}15.1 \\
15.8\end{array}$ & 0.874 & $\begin{array}{l}104 \\
38\end{array}$ & $\begin{array}{l}42.4 \\
40.0\end{array}$ & $\begin{array}{l}141 \\
57\end{array}$ & $\left|\begin{array}{l}57.6 \\
60.0\end{array}\right|$ & 0.681 \\
\hline $\begin{array}{l}\text { Presence of } \\
\text { chronic } \\
\text { physical } \\
\text { illness:• } \\
\text { Yes } \\
\text { No }\end{array}$ & $\begin{array}{l}15 \\
241\end{array}$ & $\begin{array}{l}100 . \\
74.2\end{array}$ & $\begin{array}{l}0 \\
84\end{array}$ & $\begin{array}{l}0.0 \\
25.8\end{array}$ & $0.027 * \neq$ & $\begin{array}{l}11 \\
277\end{array}$ & $\begin{array}{l}73.3 \\
85.2\end{array}$ & & $\begin{array}{l}26.7 \\
14.8\end{array}$ & $0.261 \neq$ & $\begin{array}{l}12 \\
130\end{array}$ & & & $\begin{array}{l}20.0 \\
60.0\end{array} \mid$ & $0.002 *$ \\
\hline $\begin{array}{l}\text { Presence of } \\
\text { chronic } \\
\text { psychological } \\
\text { illness:•• } \\
\text { Yes } \\
\text { No } \\
\end{array}$ & $\begin{array}{l}16 \\
240\end{array}$ & $\begin{array}{l}61.5 \\
76.4\end{array}$ & $\begin{array}{l}10 \\
74\end{array}$ & $\begin{array}{l}38.5 \\
23.6\end{array}$ & 0.091 & $\begin{array}{l}21 \\
267\end{array}$ & $\begin{array}{l}80.8 \\
85.0\end{array}$ & & $\begin{array}{l}19.2 \\
15.0 \\
\end{array}$ & 0.767 & $\begin{array}{l}23 \\
119 \\
\end{array}$ & & & $\begin{array}{l}11.5 \\
62.1 \\
\end{array}$ & $0.000 *$ \\
\hline
\end{tabular}

Chi-square test, $\neq$ Fisher Exact test, $*$ Statistical significant difference $(P<0.05), \bullet$ Examples:

Diabetes, hypertension and bronchial asthma, $\bullet$ Examples: Schizophrenia and obsession 
Table (4): Logistic regression analysis of predictors of depression, anxiety and stress among the studied students

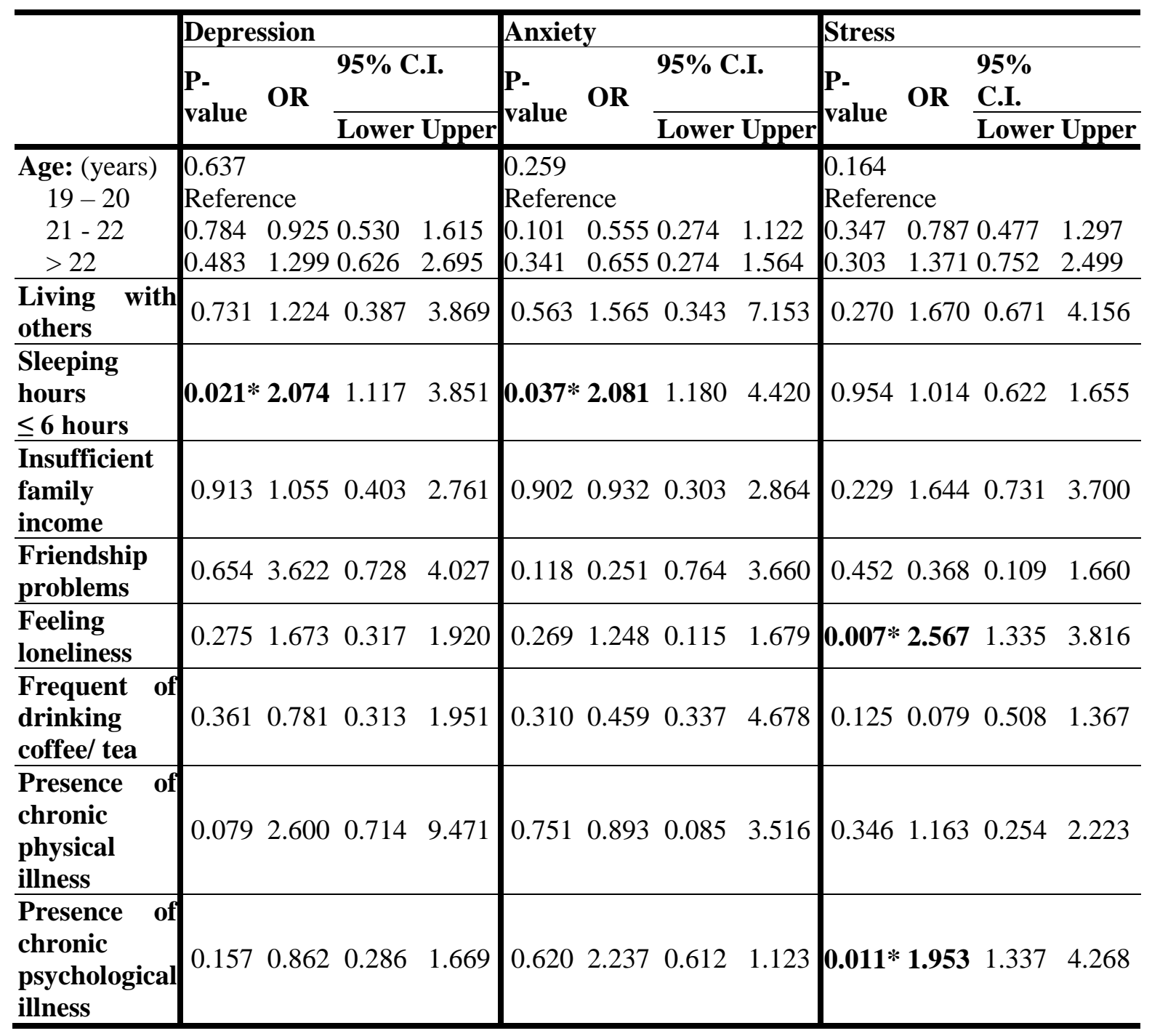




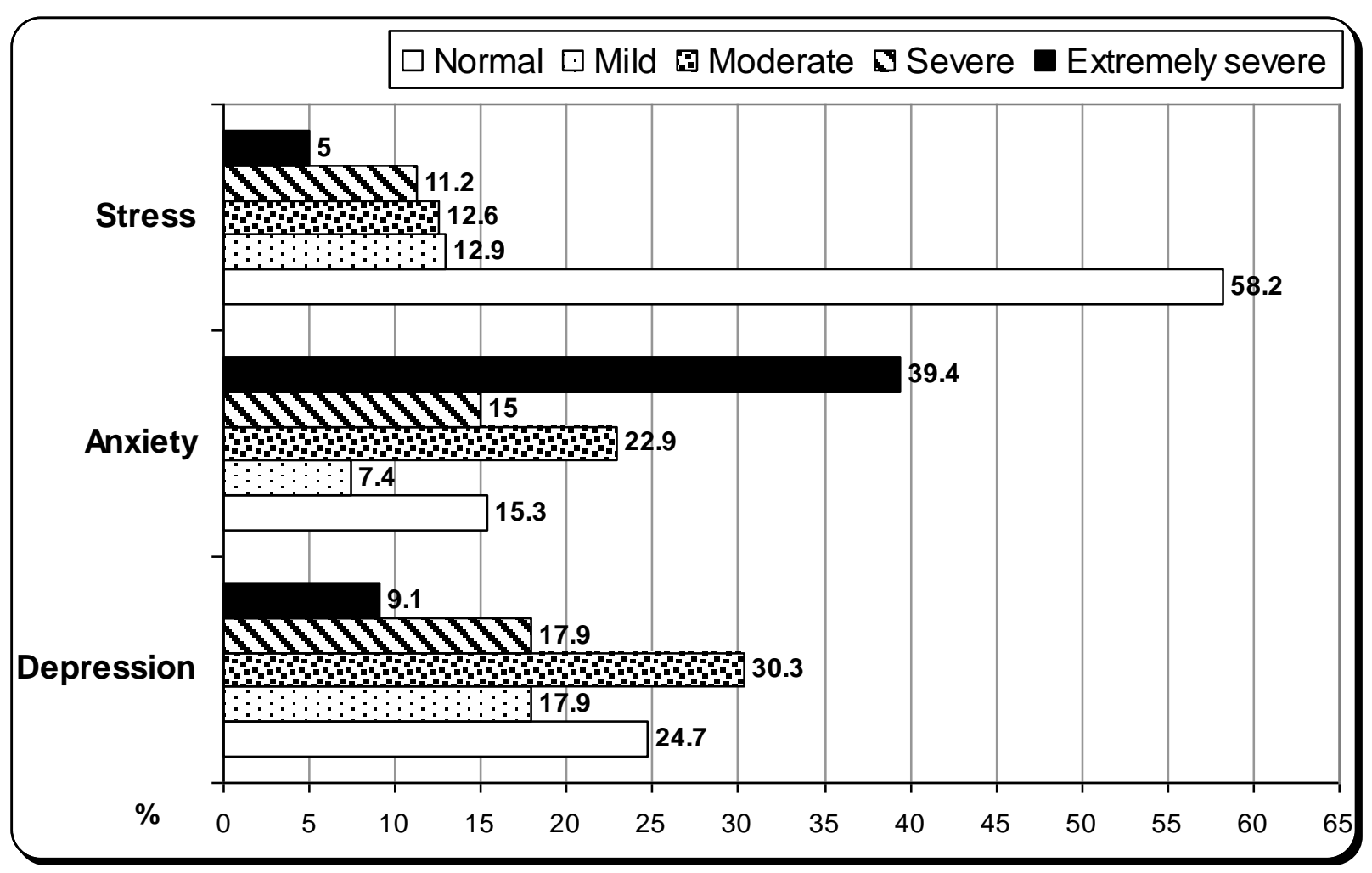

Figure (1): Severity of symptoms of depression, anxiety and stress among the studied students 

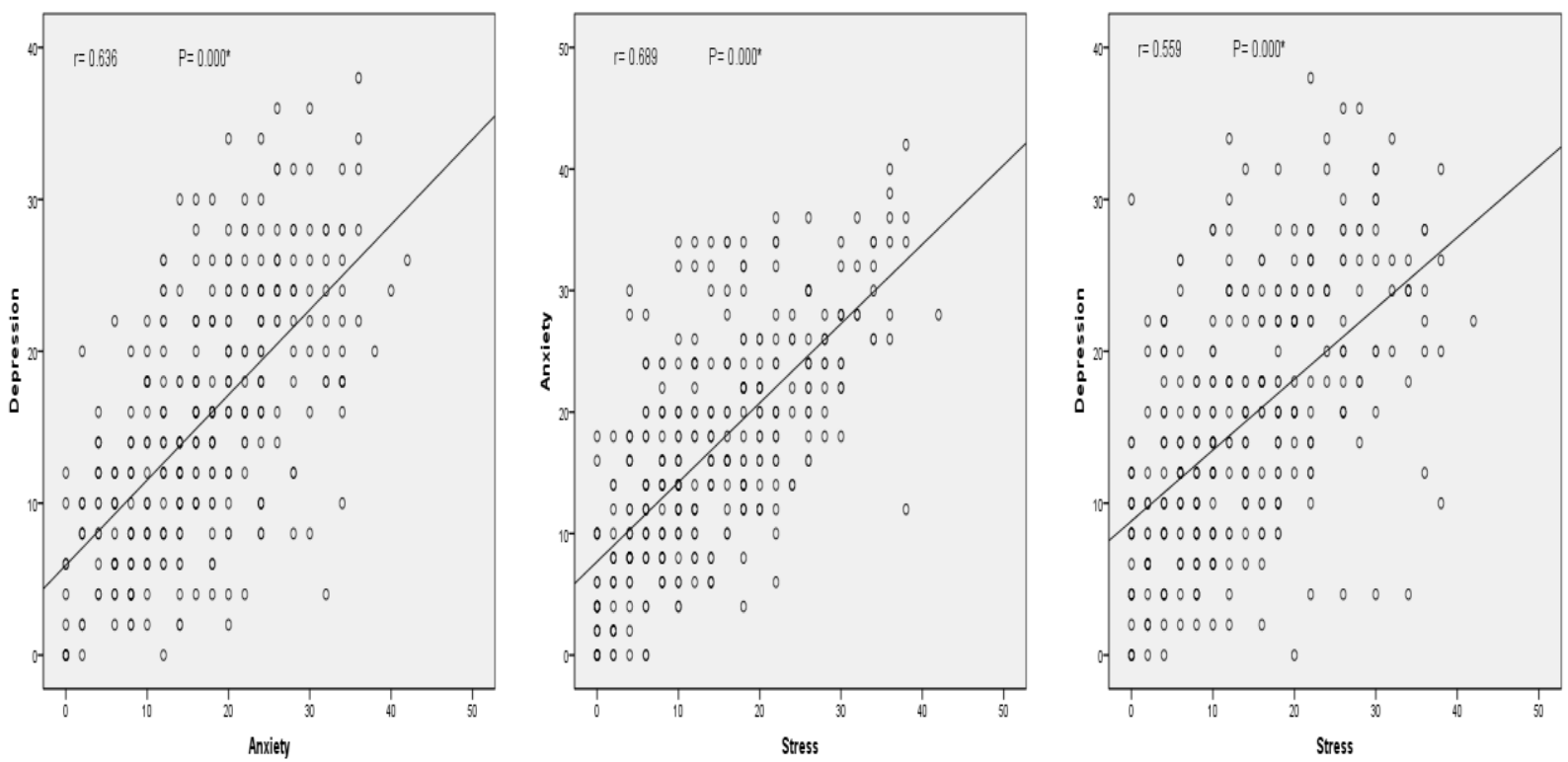

Figure (2): Correlation between severities of depression, anxiety and stress symptoms among the studied students 